\title{
IMUNODIAGNÓSTICO DA NEUROCISTICERCOSE: TESTE IMUNOENZIMÁTICO COM ANTIGENOS QUIMICAMENTE LIGADOS A SUPORTES PARA PESQUISA DE ANTICORPOS EM SORO E LÍQUIDO CEFALORRAQUIANO
}

\author{
Adelaide José VAZ (1) \& Antonio Walter FERREIRA (2)
}

\section{R E $\quad \mathbf{S} \quad \mathbf{U}$ M O}

Foi padronizado o teste imunoenzimático, ELISA, utilizando-se componentes antigênicos de Cysticercus cellulosae quimicamente ligados a suportes sólidos constituídos de discos de tecido-resina (ELISA-d), para pesquisa de anticorpos em soro líquido cefalorraquiano (LCR), ensaiando-se uma única diluição do espécime clínico. O suporte tecido-resina foi composto de tecido de poliéster impregnado com resina polimerizada de $\mathrm{N}$-metilol-acrilamida, apresentando grupos $\mathrm{N}$-metilol livres, capazes de reagir covalentemente com grupos funcionais de proteínas e polissacarídeos pre sentes no extrato antigênico salino total obtido de cisticercos. Foram ensaiados 38 soros e 74 LCR de pacientes com neurocisticercose comprovada e 50 soros e 107 LCR do grupo controle (pacientes com quadros clínicos neurológicos diversos e indivíduos supostamente normais). Obtivemos os seguintes índices de sensibilidade e especificidade: $94,7 \%$ e $92,0 \%$ para o teste realizado no soro e $98,6 \%$ e $100 \%$ para o teste realizado no LCR. O teste ELISA-d mostrou-se eficiente para o diagnóstico da neurocisticercose, principalmente quando realizado no LCR, com vantagens de estabilidade, facilidade de execução e baixo custo.

UNITERMOS: Neurocisticercose; Imunodiagnóstico da neurocisticercose; Teste imunoenzimático ELISA; ELISA.

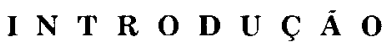

A cisticercose, doença que envolve complexa relação hospedeiro-parasita, representa importante problema de Saúde Pública, principalmente nos países do mundo onde fatores sócio-econômicos e culturais permitem sua disseminação e persistência.
A maior importância do complexo teníase cisticercose humana, decorre da localizaçāo fre qüente do cisticerco no sistema nervoso e seus envoltórios. De fato, a neurocisticercose é a mais importante, geralmente grave e a mais estudada das doenças parasitárias do sistema nervoso ${ }^{17}$.

Este trabalho é parte da Dissertação de mestrado da autora - Faculdade de Ciéncias Farmacêticas da Universidade de Sào Paulo.

(1) Instituto Adolfo Lutz. Laboratório de Imunodiagnóstico. Divisảo de Biologia Médica. Sāo Paulo, SP, Brasil.

(2) Instituto de Medicina Tropical de São Paulo. Laboratório de Soroepidemiologia. Departamento de Moléstias Infecciosas e Parasitárias. Sáo Paulo, SP, Brasil.

Endereço para correspondência: Dra. Adelaide José Vaz. Instituto Adolfo Lutz. Av. Dr. Arnaldo, 351 - $10^{\circ}$ andar - CEP 01246 - São Paulo, SP, Brasil. 
VAZ, A. J. \& FERREIRA, A. W. - Imunodiagnóstico da neurocisticercose: teste imunoenzimático com antígenos quimicamente ligados a suportes para pesquisa de anticorpos em soro e liquido cefalorraquiano. Rev. Inst. Med. trop. Sáo Paulo, 30 (1): $1-10,1988$

O Cysticercus cellulosae no sistema nervoso e nas meninges costuma determinar alteraçōes no liquido cefalorraquiano. LANGE em $1940^{9}$, conceituou a "Síndrome liquórica da neurocisticercose", cujo elemento de certeza diagnóstica é a demonstração de anticorpos específicos no líquido cefalorraquiano. A presença desses anticorpos, detectada através de técnicas imunológicas, fornece indicaçāo segura da doença, mesmo antes de suas manifestaçōes clínicas ${ }^{10 .}{ }^{17}$.

Recentemente o teste imunoenzimático, ELISA (Enzyme-Linked ImmunoSorbent As say), tem sido utilizado em soro e líquido cefalorraquiano para o imunodiagnóstico da neurocisticercose, por apresentar alta sensibilidade e especificidade, além de boa reprodutibilidade $e^{1.5}$ 6. $7.10,12$

O presente trabalho teve por objetivo a padronização do teste ELISA utilizando como supor te sólido, tecido de poliéster impregnado com resina polimerizada de $\mathrm{N}$-metilol-acrilamida (NMA), que apresenta grupos N-metilol livres ca pazes de reagir covalentemente com grupos funcionais de proteínas e polissacarideos presentes no extrato antigênico utilizado ${ }^{15}$.

\section{MATERIAL E MÉTODOS}

EXTRATO ANTIGÊNICO. O antígeno salino total de Cysticercus cellulosae (ST) foi obtido conforme metodologia descrita por COSTA ${ }^{6}$, com algumas modificaçōes. Cerca de 200 cisticercos, obtidos de músculos e vísceras de suínos infectados naturalmente, e exaustivamente lavados em soluçāo salina ( $\mathrm{NaCl} 0,15 \mathrm{M})$, foram homogeneizados (Potter-Scientific Glass Appa ratus Inc., USA) em $10 \mathrm{ml}$ de água destilada, por 20 minutos, em banho de gelo. O material foi submetido a tratamento por ultra-som (Thorton-Inpec eletrônica, Brasil) com $20 \mathrm{Khz}, 1 \mathrm{~mA}$, por quatro períodos de 60 segundos, em banho de gelo. Após isotonizaçāo com $10 \mathrm{ml}$ de solução salina ( $\mathrm{NaC} 10,3 \mathrm{M})$, a mistura foi novamente tratada com ultra-som e deixada sob lenta agitação a $4^{\circ} \mathrm{C}$ por 18 horas. A suspensāo obtida foi centrifugada a $6500 \mathrm{~g}$ por 30 minutos a $4^{\circ} \mathrm{C}$ e, o sobrena dante novamente centrifugado a $9000 \mathrm{~g}$. O sobrenadante obtido após a última centrifugação, antígeno ST, foi dividido em alíquotas de $1 \mathrm{ml} \mathrm{e}$ liofilizado. $\mathrm{O}$ antígeno foi caracterizado quanto às concentraçōes proteíca ${ }^{3}$ e polissacaridica ${ }^{16}, \mathrm{e}$ quanto à atividade antigênica por titulaçāo em bloco.

AMOSTRAS DE SORO E LIQUIDO CEFA LORRAQUIANO (LCR). Foram estudados dois grupos de amostras: de pacientes com neurocis ticercose comprovada e do grupo controle. No grupo de pacientes com neurocisticercose foram selecionados 74 casos, de 38 foram coletadas amostras de soro e LCR, e dos 36 restantes somente amostras de LCR. Das 74 amostras de LCR obtidas, 34 apresentavam reação de fixação de complemento negativa para cisticercose. No - grupo controle foram estudadas 29 amostras de soro e 40 amostras de LCR de 40 indivíduos supostamente normais; também foram incluídas neste grupo 21 amostras de soro e 67 amostras de LCR de 67 pacientes com outros processos patológicos do sistema nervoso (meningite, neu rossifilis, acidente vascular, tumores, coma, he morragia intracraniana pós-trauma).

TESTE IMUNOENZIMÁTICO ELISA EM DISCOS (ELISA-d). Foram utilizados discos de poliéster com $6 \mathrm{~mm}$ de diâmetro, impregnados com N-metilol-acrilamida como suporte sólido para o teste ELISA-d.

1. Sensibilizaçâo dos discos. Aos discos, lava dos em PBS pH 7,2 (fosfatos $0,01 \mathrm{M}-\mathrm{NaCl}$ $0,14 \mathrm{M}$ ) e secos, foi adicionado o antígeno $\mathrm{ST}$ diluído em PBS, na proporção de $1 \mathrm{ml}$ para cada seis discos. Após incubaçóes de 2 horas a $37^{\circ} \mathrm{C}$ e 18 horas a $4^{\circ} \mathrm{C}$ sob lenta rotação, os discos foram lavados três vezes com PBS e incubados com solução bloqueadora (PBS contendo $0,05 \%$ de Tween-20 e $2 \%$ de gelatina) por 2 horas a $37^{\circ} \mathrm{C}$, para bloqueio dos sítios ativos remanescentes. Após novas la vagens, os discos foram secos entre folhas de papel-filtro e armazenados a $4^{\circ} \mathrm{C}$ em fras cos fechados.

2. Execução do teste. Cada amostra de soro e LCR foi diluida em duplicata, ern PBS-TG (PBS contendo $0,05 \%$ de Tween-20 e $0,5 \%$ de gelatina), em volume final de $0,2 \mathrm{ml}$. Os soros foram diluídos a 1:40 e os LCR a 1:4. A cada tubo de diluição adicionou-se um disco sensibilizado. Após incubaçāo de 45 minutos a $37^{\circ} \mathrm{C}$, os discos foram lavados três vezes, 5 minutos cada, com PBS-T. Os discos foram 
VAZ, A. J. \& FERREIRA, A. W. - Imunodiagnóstico da neurocisticercose: teste imunoenzimático com antigenos quimicamente ligados a suportes para pesquisa de anticorpos em soro e líquido cefalorraquiano. Rev. Inst. Med. trop. Sáo Paulo, 30 (1): $1-10,1988$.

incubados com $0,2 \mathrm{ml}$ do conjugado imu noenzimático, anti-IgG-fosfatase alcalina (Sigma Chemical Co., USA), diluído segundo o título em PBS-TG. Após novas lavagens, os discos foram transferidos de tubos e a reaçāo enzimática iniciada pela adiçāo de 0,25 $\mathrm{ml}$ da soluçāo cromógena (p-nitro-fenil-fos fato dissódico em soluçāo de dietanolamina $\mathrm{pH} 9,8 \mathrm{na}$ proporção de $1 \mathrm{mg} / \mathrm{mll}$, e foi interrompida com $1 \mathrm{ml}$ de $\mathrm{NaOH} 2 \mathrm{M}$ após incubaçāo de 30 minutos a $37^{\circ} \mathrm{C}$. A reatividade foi avaliada em espectrofotometro (Spectronic 21, Bausch \& Lomb, USA) em comprimento de onda de $405 \mathrm{~nm}$.

3. Cálculo dos títulos dos soros e LCR. Para verificação da proporcionalidade entre a reatividade do teste e quantidade de anticorpos, expressa como diluiçōes das amostras, procederam-se a ensaios com amostras de soro e LCR de pacientes com neurocisticercose e de individuos supostamente normais. Para avaliaçāo da variação de densidade óptica (DO) em relaçāo à diluiçāo ensaiada (Curvas de Reatividade), os padrōes positivos de soro e LCR foram ensaiados em ocasióes diferen tes. A partir da curva de reatividade padrão obtida para cada espécime, foram calculados os coeficientes angulares $(k)$ dados pela relação entre acréscimos de DO e acréscimos das respectivas diluições ( $\Delta \log \mathrm{DO} / \Delta \log$ diluiçāo). A constância da inclinação angular permite calcular os títulos das amostras a partir

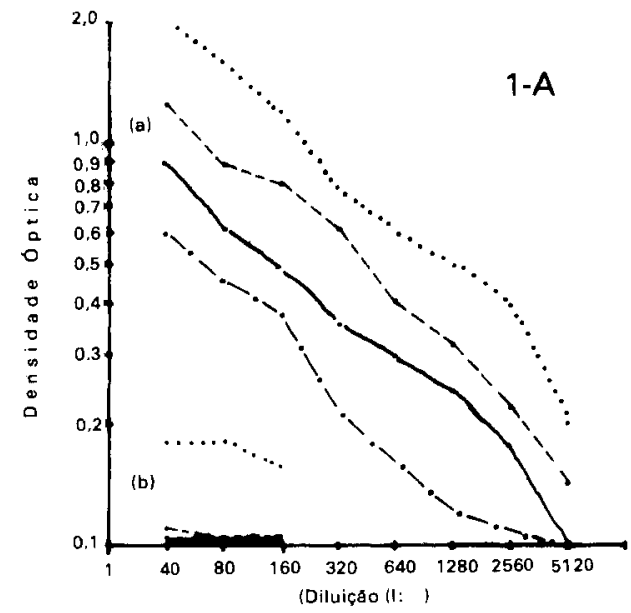

do ensaio de uma única diluiçāo, através da equação:

$$
\mathrm{T}=\log \mathrm{D}+\left(\frac{\log \mathrm{a}-\log \mathrm{b}}{\mathrm{k}}\right),
$$

onde $\mathrm{T}$ é o título a ser determinado; $\mathrm{D}$ a diluiçāo ensaiada; a é a DO obtida para D; b o "cut off"; $\mathrm{k}$ é o coeficiente angular da reta.

ANÁLISE ESTATÍsTICA. A média geométrica dos títulos (MGT) foi calculada segundo PAUL \& WHITE ${ }^{14}$. Os indices de sensibilidade, especificidade, valores preditivos positivo e negativo e a eficiência do teste ELISA-d foram calculados conforme GALEN \& GAMBINO ${ }^{8}$.

\section{RESULTADOS}

\section{Avaliação do extrato antigênico $S T$}

Para o antígeno ST, obtido de 200 cis $₫$ icercos em volume final de $20 \mathrm{ml}$, foram encontradas as concentraçōes de $6,1 \mathrm{mg} / \mathrm{ml}$ de proteínas $\mathrm{e}$ $5,2 \mathrm{mg} / \mathrm{ml}$ de polissacarídeos. A titulaçāo em bloco do antígeno ST nas concentraçōes de 5, 10, 20 e $40 \mu \mathrm{g}$ de proteínas por ml, frente aos soros e LCR padrões positivos e negativos diluídos na razào 2, soros a partir de 1:40 e LCR a partir de 1:4, é apresentada nas figuras 1-A e 1-B, respectivamente para o soro e LCR. Considerando-se os "cut-off" do teste realizado em soro de 0,150 e em LCR de 0,100 , a concentração de 20 $\boldsymbol{\mu} \mathrm{g} / \mathrm{ml}$ foi escolhida para sensibilizar os discos.

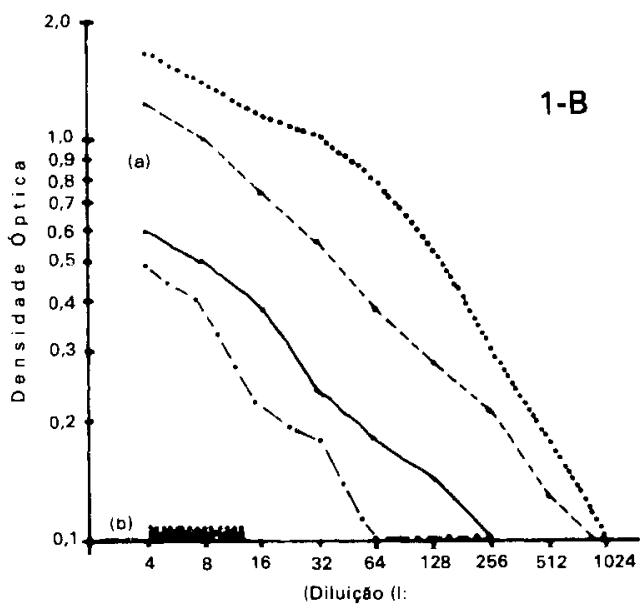

Fig. 1 - Densidades ópticas obtidas para as diluiçoes de soros (1-A) e LCR (1-B) padróes positivos (a) e negativos (b) no teste ELISA-d empregando extrato salino total de Cysticercus cellulosae nas concentraçóes de $5 \mu \mathrm{g} / \mathrm{ml}(\cdots), 10 \mu \mathrm{g} / \mathrm{ml}(-), 20$ $\boldsymbol{\mu g} / \mathrm{ml}(\ldots)$ e $40 \mu \mathrm{g} / \mathrm{ml}(\cdots \cdots)$. 
VAZ, A. J \& FERREIRA, A. W. - Imunodiagnóstico da neurocisticercose: teste imunoenzimatico com antígenos quimicamente ligados a suportes para pesquisa de anticorpos em soro e liquido cefalorraquiano. Rev. Inst. Med. trop. Sāo Paulo, 30 (1): 1-10, 1988

\section{Teste ELISA-d}

Nas figuras 2-A e 2-B são apresentadas as curvas de reatividade obtidas, respectivamente, para soros e LCR de três pacientes com neurocis ticercose e de dois individuos supostamente nor mais.
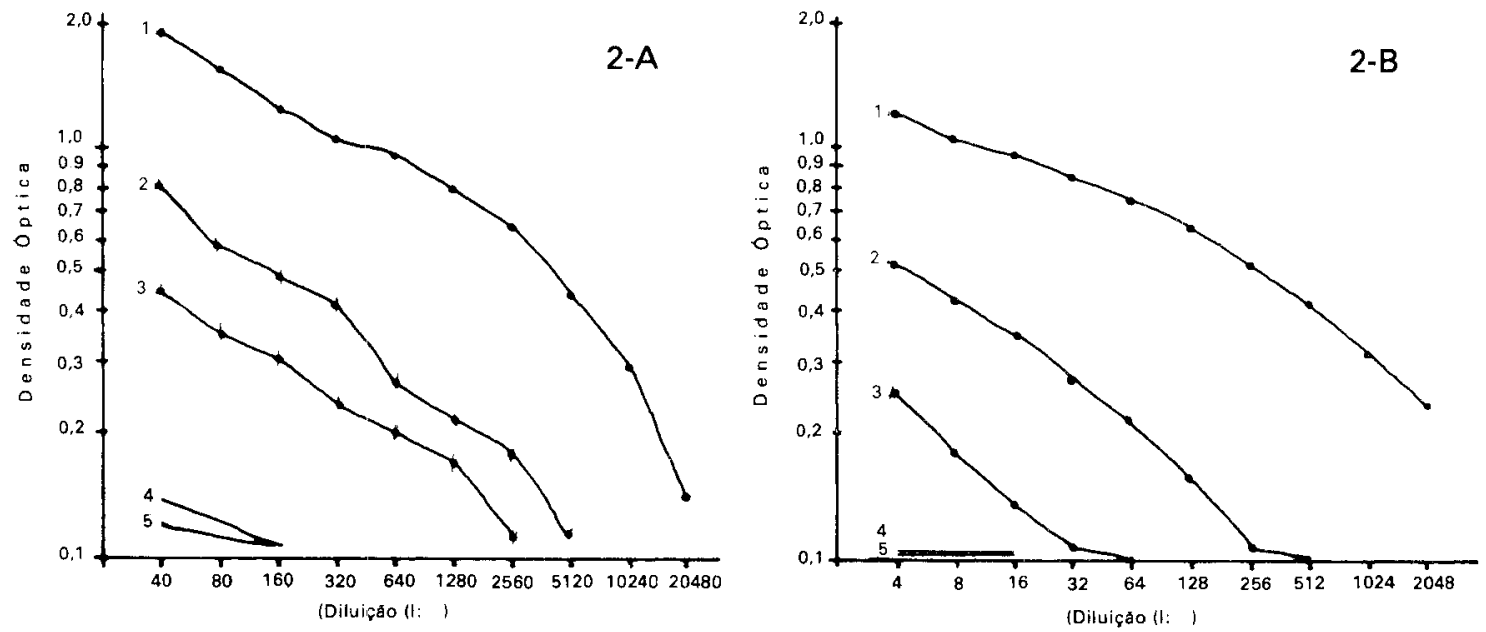

Fig. 2 - Curvas de reatividade obtidas no teste ELISA d para soros (2-A) e LCR (2-B) de pacientes com neurocisticercose $(1,2,3)$ e de individuos supostamente normais $\{4,5)$.

Os padrões positivos de soro e LCR foram ensaiados em 10 ocasióes diferentes, e a média e os limites de variaçāo de DO, respectivamente para cada diluição de soro e LCR, sảo apresen tadas nas figuras 3-A e 3-B. Esses padrōes positi vos foram diluídos a 1:16 e 1:32, respectivamente em soro e LCR normais, para obtenção de um segundo padrāo positivo para cada espécime As figuras 4-A e 4-B mostram as curvas de reati vidade obtidas para os dois padrōes, respectiva mente de soro e LCR.
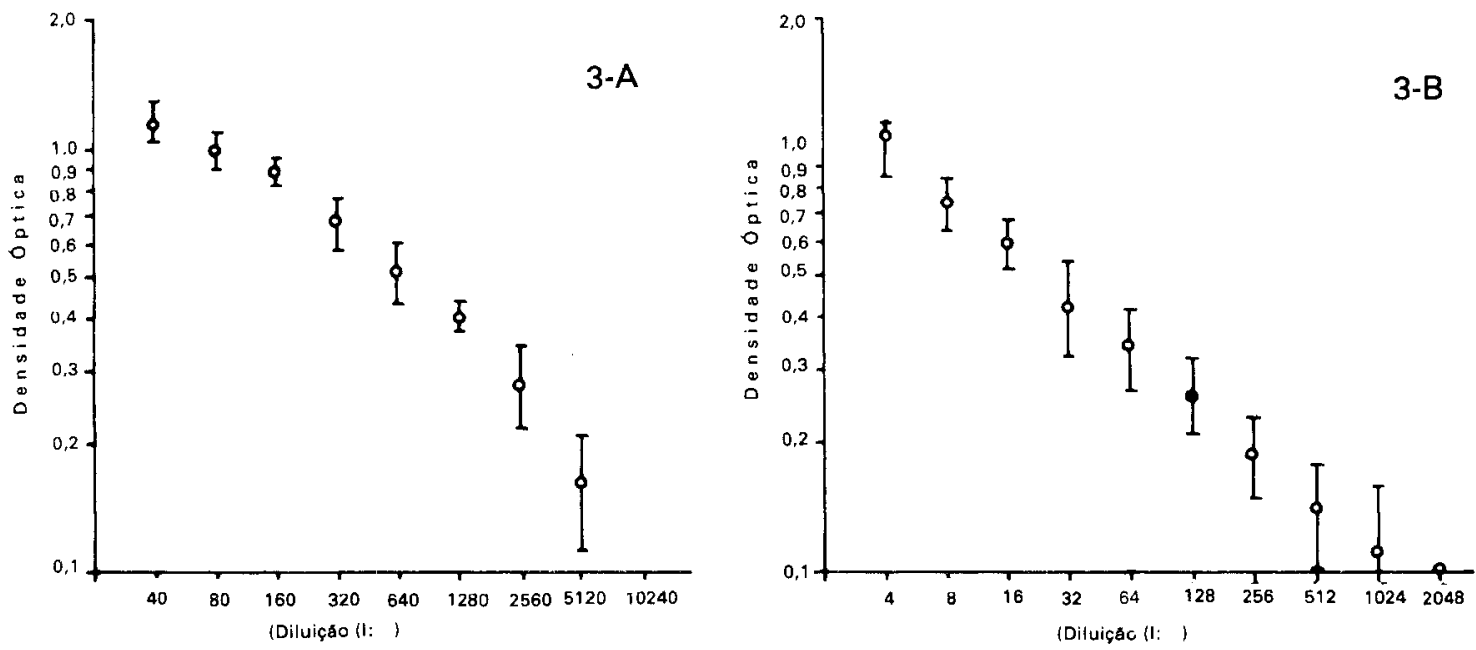

Fig. 3 - Média e limites de variação das densidades ópticas obtidas em 10 titulaçóes do soro padrão positivo (3-A) e do LCR padrão positivo (3-B) no teste ELISA d. 
VAZ, A. J. \& FERREIRA, A. W. - Imunodiagnóstico da neurocisticercose: teste imunoenzimático com antigenos quimicamente ligados a suportes para pesquisa de anticorpos em soro e liquido cefalorraquiano. Rev. Inst. Med. trop. São Paulo, 30 (1): $1-10,1988$.
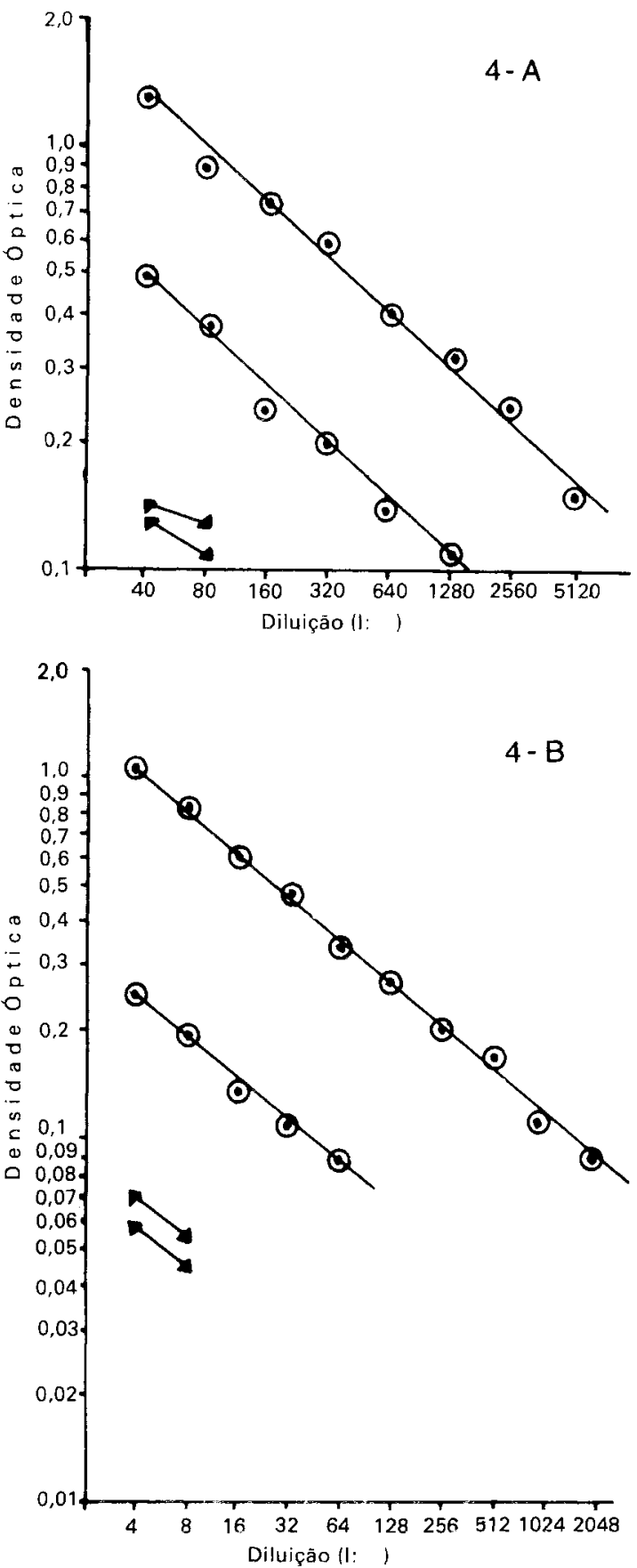

Fig. 4 - Curvas de reatividade dos soros (4-A) e LCR (4-B) padróes positivos $(\theta)$ e negativos $(\rightarrow$ ) obtidas no teste ELISA.d.

As retas obtidas permitiram calcular o coeficiente angular $\mathrm{k}(\mathbf{\Delta} \log \mathrm{DO} / \mathbf{\Delta} \log$ dil.) de 0,43 para a curva de reatividade de soro e 0,44 para a de LCR. Considerando a constante proporcionalidade entre DO e concentração de anticorpos da amostra, os títulos foram calculados a partir do ensaio de uma única diluição do espécime, através das equaçōes:

$\mathrm{T}=\log 40+\left(\frac{\log \mathrm{a}-\log 0,150}{0,43}\right)$

onde T é o título e "a" a DO obtida para a diluiçāo 1:40 do soro:

$\mathbf{T}=\log 4+\left(\frac{\log \mathrm{a}-\log 0,100}{0,44}\right)$

onde T é o título e "a" a DO obtida para a dilui çāo 1:4 do LCR. Foram considerados positivos os títulos iguais ou maiores que 1,60 (1:40) para soros, e iguais ou maiores que $0,60(1: 4)$ para LCR.

Na tabela 1 é apresentada a distribuição dos soros de LCR dos dois grupos estudados, com neurocisticercose e controle, segundo título obtido no teste ELISA-d.

A partir dos resultados obtidos nas amostras estudadas foram calculados os indices de sensibilidade e especificidade. Para os soros obtivemos sensibilidade de $94,7 \%$ com intervalo de confiança de $95 \%$ de probabilidade (IC) de $87,5 \%$ a $100 \%$, e especificidade de $92,0 \%$ com IC de $84,3 \%$ a $99,7 \%$ : para o estudo dos LCR a sensibilidade obtida foi de $98,6 \%$ (IC de $95,9 \%$ a $100 \%$ ) e a especificidade de $100 \%$ (IC de $97,5 \%$ a $100 \%$ ).

As médias geométricas dos títulos dos soros no teste ELISA-d foram 2,64 (1:436) e 0,74 (1:6), respectivamente para soros de pacientes com neurocisticercose e soros do grupo controle. Para os títulos dos LCR do grupo de doentes a média geométrica foi $2,13(1: 135)$ e para os LCR do grupo controle foi de 0,11 (1:1).

Os valores preditivos positivo e negativo e a eficiencia do teste ELISA-d foram calculados para diferentes prevalências da neurocisticercose: $100,1.000$ e 10.000 casos por 100.000 habitantes ou, respectivamente, $0,1 \%, 1 \%$ e $10 \%$. Estes resultados são apresentados na tabela 2 . 
VAZ, A. J. \& FERREIRA, A. W. - Imunodiagnóstico da neurocisticercose: teste imunoenzimático com antígenos quimicamente ligados a suportes para pesquisa de anticorpos em soro e líquido cefalorraquiano. Rev. Inst. Med. trop. São Paulo, 30 (1): $1 \cdot 10,1988$.

TABELA 1

Distribuiçáo dos soros e liquidos cefalorraquianos (LCR) dos pacientes com neurocisticercose (a) e do grupo controle (b). segundo títulos obtidos no teste ELISA d. (vide texto. pägina 5 ).

\begin{tabular}{|c|c|c|c|c|c|c|c|c|c|c|c|c|}
\hline \multirow[b]{2}{*}{ Espécime } & \multirow[b]{2}{*}{ Grupo } & \multicolumn{10}{|c|}{ TITULOS } & \multirow[b]{2}{*}{ Total } \\
\hline & & $\begin{array}{c}0 \\
\mathrm{a} \\
1,59\end{array}$ & $\begin{array}{c}1,60 \\
a \\
1,89\end{array}$ & $\begin{array}{c}1,90 \\
\mathrm{a} \\
2,19\end{array}$ & $\begin{array}{c}2,20 \\
\text { a } \\
2,49\end{array}$ & $\begin{array}{c}2,50 \\
a \\
2.79\end{array}$ & $\begin{array}{c}2,80 \\
\mathrm{a} \\
3,09\end{array}$ & $\begin{array}{c}3,10 \\
\mathrm{a} \\
3,39\end{array}$ & $\begin{array}{c}3.40 \\
\mathrm{a} \\
3,70\end{array}$ & $\begin{array}{c}3,71 \\
a \\
4,00\end{array}$ & $\begin{array}{c}4,01 \\
a \\
4,30\end{array}$ & \\
\hline $\mathrm{s}$ & a & 2 & 7 & 2 & 3 & 8 & 5 & 7 & 1 & 2 & 1 & 38 \\
\hline $\begin{array}{l}R \\
O\end{array}$ & $b$ & 46 & 1 & - & 2 & 1 & - & - & - & - & - & 50 \\
\hline & & $\begin{array}{c}0 \\
a \\
0,59\end{array}$ & $\begin{array}{c}0,60 \\
\text { a } \\
0,89\end{array}$ & $\begin{array}{c}0,90 \\
\text { a } \\
1,19\end{array}$ & $\begin{array}{c}1,20 \\
\mathrm{a} \\
1.49\end{array}$ & $\begin{array}{c}1,50 \\
\mathrm{a} \\
1,80\end{array}$ & $\begin{array}{c}1,81 \\
a \\
2,10\end{array}$ & $\begin{array}{c}2,11 \\
\mathrm{a} \\
2,40\end{array}$ & $\begin{array}{c}2.41 \\
\mathrm{a} \\
2,70\end{array}$ & $\begin{array}{c}2.71 \\
\mathrm{a} \\
3.00\end{array}$ & $\begin{array}{c}3,01 \\
\mathrm{a} \\
3,30\end{array}$ & Total \\
\hline $\begin{array}{l}\mathrm{L} \\
\mathrm{C} \\
\mathrm{R}\end{array}$ & $\begin{array}{l}a \\
b\end{array}$ & $\begin{array}{c}1 \\
107\end{array}$ & $\begin{array}{l}1 \\
-\end{array}$ & $\begin{array}{l}1 \\
-\end{array}$ & $\begin{array}{l}12 \\
-\end{array}$ & $\begin{array}{l}6 \\
-\end{array}$ & $\begin{array}{l}12 \\
-\end{array}$ & $\begin{array}{l}15 \\
-\end{array}$ & $\begin{array}{l}13 \\
-\end{array}$ & $\begin{array}{l}8 \\
-\end{array}$ & $\begin{array}{l}5 \\
-\end{array}$ & $\begin{array}{c}74 \\
107\end{array}$ \\
\hline
\end{tabular}

TABELA 2

Valores preditivos positivo e negativo e eficiencia do teste ELISA d realizado em soro e liquido cefalorraquiano (LCR) segundo prevalência da neurocisticercose

\begin{tabular}{|c|c|c|c|}
\hline \multirow{2}{*}{ Indice } & \multirow{2}{*}{$\begin{array}{c}\text { Prevalència } \\
\left(c_{/ r}\right)\end{array}$} & \multicolumn{2}{|c|}{ Espécime } \\
\hline & & Soro & $\mathrm{LCR}$ \\
\hline $\begin{array}{l}\text { Valor preditivo } \\
\text { positivo }(\%)\end{array}$ & $\begin{array}{r}0.1 \\
1.0 \\
10.0\end{array}$ & $\begin{array}{r}1 \\
11 \\
57\end{array}$ & $\begin{array}{l}100 \\
100 \\
100\end{array}$ \\
\hline $\begin{array}{l}\text { Valor preditivo } \\
\text { negativo }(c / c)\end{array}$ & $\begin{array}{r}0,1 \\
1,0 \\
10,0\end{array}$ & $\begin{array}{r}100 \\
100 \\
99\end{array}$ & $\begin{array}{l}100 \\
100 \\
100\end{array}$ \\
\hline $\begin{array}{l}\text { Eficiência do teste } \\
\text { ELISA d }(\%)\end{array}$ & $\begin{array}{r}0,1 \\
1,0 \\
10,0\end{array}$ & $\begin{array}{l}92 \\
92 \\
92\end{array}$ & $\begin{array}{l}100 \\
100 \\
100\end{array}$ \\
\hline
\end{tabular}

As 88 amostras pareadas de soro e LCR, 38 de pacientes com neurocisticercose e 50 do grupo controle foram estudadas quanto à reatividade apresentada no teste ELISA-d. A tabela 3 mostra a relação entre o resultado de LCR com o resul tado da amostra pareada de soro. Considerando que o teste realizado no $L C R$ oferece o resultado de referência para o diagnóstico da neurocisticercose, foram obtidos os índices de co-positi- vidade de 0,973 , de co-negatividade de 0,922 e concordancia de 0,943 com os resultados do teste realizado no soro correspondente.

TABELA 3

Resultados comparativos do teste ELISA-d segundo reatividade de amostras pareadas, soro e liquido cefalorraquiano ( $L C R$ )

\begin{tabular}{c|c|ccc}
\hline \multirow{2}{*}{ Espécime } & \multicolumn{4}{|c}{ L C R } \\
\cline { 2 - 5 } & Reatividade & \multicolumn{4}{|c}{$\mathrm{R}$} & $\mathrm{NR}$ & $\mathrm{T}$ \\
\hline $\mathrm{S}$ & $\mathrm{R}$ & 36 & 4 & 40 \\
$\mathrm{O}$ & $\mathrm{NR}$ & 1 & 47 & 48 \\
$\mathrm{R}$ & $\mathrm{T}$ & 37 & 51 & 88 \\
$\mathrm{O}$ & & & & \\
\hline
\end{tabular}

$R=$ reagente; $N R=$ náo reagente; $T=$ total

A reprodutividade intra-ensaio do teste foi avaliada através dos resultados de densidade óptica (DO) de 20 amostras reagentes e 20 nāoreagentes ensaiadas em duplicata (Figura 5 ). $\mathrm{Na}$ figura 6 são apresentados os resultados da avaliação in terensaio de 25 soros e 25 L,CR ensaiados em dias diferentes. 
VAZ, A. J. \& FERREIRA, A. W. - Imunodiagnóstico da neurocisticercose: teste imunoenzimático com antigenos quimicamente ligados a suportes para pesquisa de anticorpos em soro e liquido cefalorraquiano. Rev. Inst. Med. trop. São Paulo, 30 (1): 1 - 10,1988
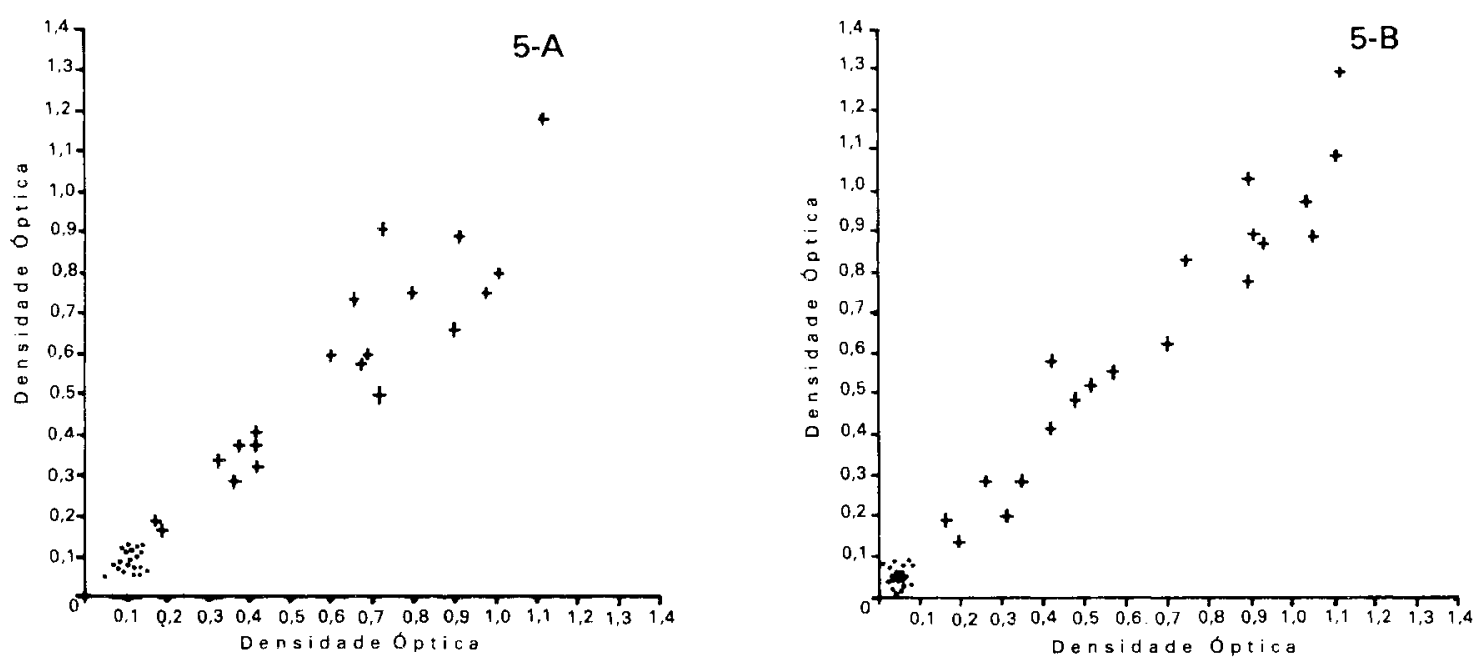

Fig 5 - Reprodutibilidade intra ensaio do teste ELISA d. Densidades opticas das amostras de soro 15 Ale liquido cefalorra quiano 15 -B) ensaiadas em duplicata. sendo 20 reagentes $(+)$ e 20 nà-reagentes $i$, .
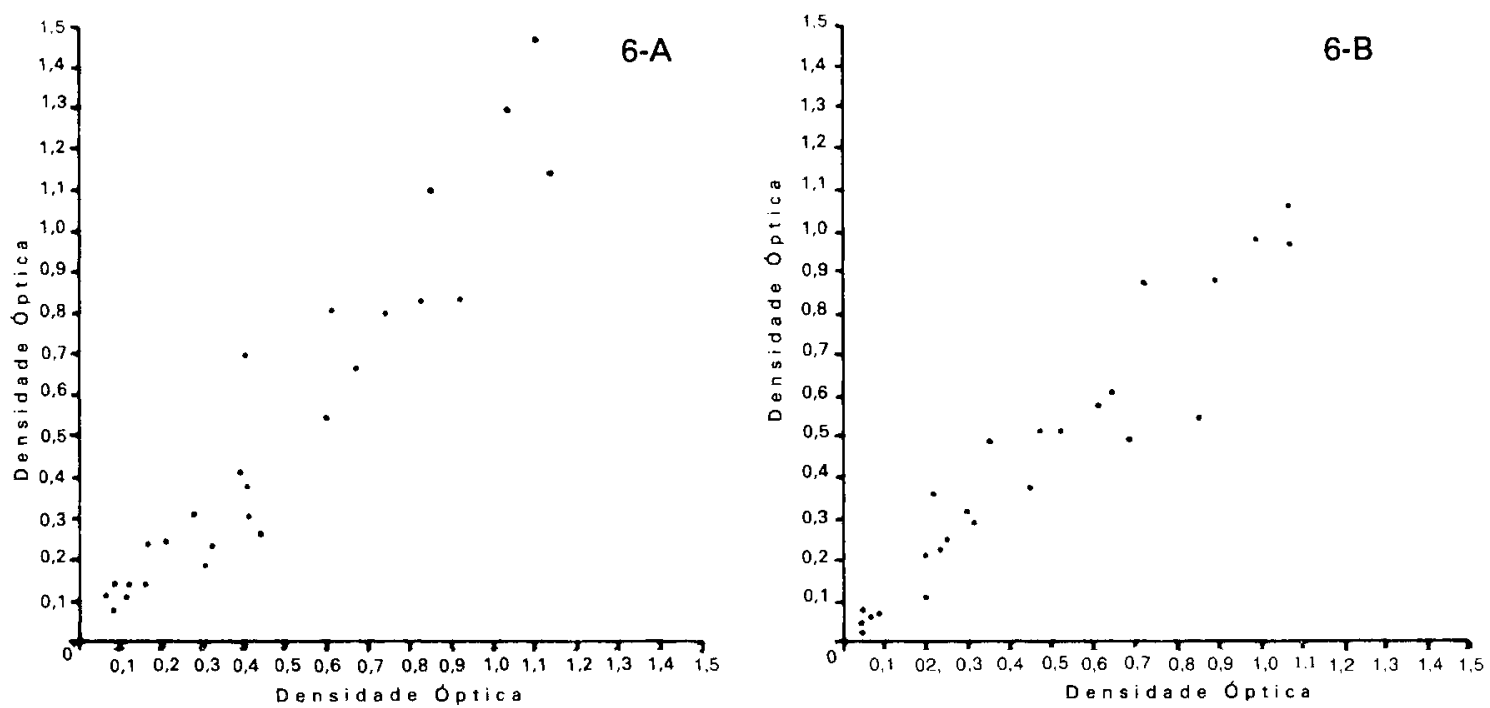

Fig. 6 - Reprodutibilidade interensaio do teste ELISA-d. Densidades ópticas de 25 soros (6 A) e 25 LCR (6-B) ensaiados em dias diferentes

\section{Estabilidade dos discos sensibilizados}

Discos sensibilizados com $20 \mu \mathrm{g} / \mathrm{ml}$ do antígeno $\mathrm{ST}$ foram bloqueados e armazenados a $4^{\circ} \mathrm{C}$.
A reatividade dos discos foi avaliada, 5, 10, 15 e 20 dias após o armazenamento, frente aos pa drōes de soro e LCR e os resultados são apresentados na tabela 4 
VAZ. A. J. \& FERREIRA, A. W. - Imunodiagnóstico da neurocisticercose: teste imunoenzimático com antigenos quimicamente ligados a suportes para pesquisa de anticorpos em soro e liquido cefalorraquiano. Rev. Inst. Med. trop. São Paulo, 30 (1): $1-10,1988$

TABELA 4

Densidades opticas obtidas no teste ELISA d para as diluicoes 1:80 e 1:8, respectivamente. do soro e LCR padroes positivos. segundo tempo de armazenamento dos discos sensibilizados a $4^{\prime \prime} \mathrm{C}$

\begin{tabular}{c|cc}
\hline \multirow{2}{*}{$\begin{array}{c}\text { Tempo de } \\
\text { armazenamento } \\
\text { (Dias) }\end{array}$} & \multicolumn{2}{|c}{ Especime } \\
\cline { 2 - 3 } & $\begin{array}{c}\text { Soro positivo } \\
1: 80\end{array}$ & $\begin{array}{c}\text { LCR positivo } \\
1.8\end{array}$ \\
\hline 5 & 1.090 & 0.978 \\
10 & 0.982 & 0.976 \\
15 & 0.852 & 0.800 \\
20 & 0.952 & 0.852 \\
\hline
\end{tabular}

\section{DISCUSSÃO}

Foi padronizado o teste imunoenzimático, ELISA-d, com componentes antigênicos de Cysticercus cellu losae covalentemente ligados a suporte sólido, discos de poliéster ativados, para o diagnóstico da neurocisticercose em soro e líquido cefalorraquiano. O preparo do suporte-resina é simples, de fácil execução e de baixo custo. Cada $\mathrm{m}^{2}$ do suporte rende mais de 10.000 discos de $6 \mathrm{~mm}$ de diâmetro como os que foram utilizados. Este suporte, discos de poliéster impregnados com resina polimerizada de $\mathrm{N}$-metilol-acri lamida, foi escolhido pelos bons resultados que apresentou em termos de capacidade de ligação de proteinas e de estabilidade ${ }^{2.4}{ }^{15}$.

O extrato antigênico salino total (ST) empregado, apresentou rendimento bastante satisfatório. Para a sensibilizaçào de 6 discos foram necessárias $20 \mu \mathrm{g}$ de proteína antigênica, o que foi considerado um bom resultado $o^{15}$

As curvas de reatividade obtidas no teste ELISA-d, figuras 2 e 4, demonstram a linearidade entre concentração de anticorpos e densidade óptica. A reprodutibilidade dessa proporcionalidade, figura 3 , permite que se utilize uma única diluição adequada dos espécimes para avaliar a concentração de anticorpos ${ }^{4.15}$, o que vem simplificar o imunodiagnóstico da neurocisticercose e abrir novos horizontes para inquéritos epidemiológicos utilizando técnicas mais sensiveis e de baixo custo.
Os resultados do teste ELISA-d para os espécimes dos dois grupos estudados, tabela 1 , foram considerados bons. Dos 38 soros de doentes, 36 foram reagentes com títulos entre 1,62(1:42) e $4.13(1: 13490)$. Dois soros desse grupo, titulos 1,18 (1:15) e 1.59 ( $1: 39$ ) foram falso-negativos no teste. Dos 50 soros do grupo controle, somente quatro foram falso positivos, dois de pacientes com me ningite bacteriana que apresentaram títulos de $1.77(1: 59)$ e 2.55 ( $1: 355)$ e dois soros de individuos supostamente normais, com titulos de 2,21 (1:162) e 2,43 (1:270). Os quatro LCR correspon dentes a esses soros falso-positivos foram não reagentes no teste. Dos $74 \mathrm{LCR}$ de pacientes com neurocisticercose, 73 foram reagentes no teste ELISA-d, com títulos que variaram de 0,68 (1:5) e 3,24 (1:1737). Somente um LCR deste grupo. título 0,36 (1:3), foi falso-negativo. Os $107 \mathrm{LCR}$ do grupo controle foram não-reagentes no teste ELISA-d. Esses resultados forneceram altos indices de sensibilidade e especificidade, o que está de acordo com os dados de literatura para o teste clássico ELISA em placas plásticas de microtitulaçāo ${ }^{1,5,6,7,10,12}$.

A média geométrica dos títulos dos soros e LCR, demonstra que as diferenças observadas entre os dois grupos de amostras estudadas são significativas e, que o teste ELISA-d foi discriminante para os dois grupos, de doentes e controle, como já foi observado através das curvas de rea tividade obtidas para os espécimes padrōes positivos e negativos (Figura 4).

Para avaliarmos o comportamento do teste ELISA-d quando aplicado na populaçāo em ge ral, estudamos o efeito da prevalência da neuro cisticercose sobre os valores preditivos e a efi ciència do teste (tabela 2). Podemos notar que o teste realizado no $\mathrm{LCR}$ fornece melhores indices do que quando realizado no soro. Considerando que a resposta imune na neurocisticercose, freqüentemente se restringe às estruturas que circundam o parasita ${ }^{11,13}$, e pelos resultados por nós obtidos, sugerimos o LCR como o melhor espécime clínico, para os testes imunodiagnós ticos.

Comparamos os resultados do teste no LCR com os resultados no soro correspondente, tabela 3 , e observamos que houve discordância em 
VAZ, A. J \& FERREIRA, A. W. - Imunodiagnóstico da neurocisticercose: teste imunoenzimático com antigenos quimicamente ligados a suportes para pesquisa de anticorpos em soro e líquido cefalorraquiano Rev. Inst. Med. trop. Sáo Paulo, 30 (1): $1.10,1988$.

cinco casos, quatro soros falso positivos com os correspondentes LCR negativos e um soro falsonegativo com o LCR correspondente positivo.

Os coeficientes de correlação para a repro dutibilidade intra-ensaio do teste ELISA-d. figu ra 4 , foram 0.858 e 0,983 , respectivamente, para soros e LCR. Para a reprodutibilidade interen. saio, figura 6 , foram obtidos os coeficientes de 0,897 e 0,950 , respectiv́amente, soro e LCR. Estes resultados foram considerados bons, já que em nenhuma das amostras estudadas, todas ensaia das em duplicata, foi observada discrepancia de resultados.

A estabilidade dos discos sensibilizados foi avaliada, tabela 4 , e mostrou que não houve per da de reatividade até por 20 dias de armazenamento a $4^{\circ} \mathrm{C}$. Recentemente temos conservados estes discos sensibilizados por até 4 meses, sem perda significativa da atividade reativa no teste ELISA-d (dados nāo apresentados).

\section{SUMMARY}

Neurocysticercosis immunodiagnosis: immunoenzimatic assay with antigens covalently bounded on nylon treated resin to detect antibodies in CSF and sera.

The enzyme linked immunosorbent assay, ELISA, was developed in a new type of support consisting of discs of sinthetic fabric-resin (ELISA-d) with antigenic components of Cysticercus cellulosae covalently bound for detection of antibodies in sera and cerebrospinal fluid (CSF). The support fabric-resin consistis of poliester fabric coated with crosslinked resin (N-methylolacrylamide) containing $\mathbf{N}$-methylol groups able to form covalent bounds with functional groups of proteins and polysaccharides which are present in the antigenic saline extract obtained from Cysticercus cellulosae. Sera titer and CSF titer were determined using only one dilution according to the dose-response standard curves obtai ned. Thirty-eight sera and 74 CSF from patients with confirmed diagnosis of neurocysticercosis and 50 sera and 107 CSF from a control group (patients suffering from neurological disorders other than neurocysticercosis and supposedly healthy individuals) were assayed. The sensiti- vity and the specificity of ELISA-d were deter mined: $94.7 \%$ and $92.0 \%$ for sera and $98.6 \%$ and $100 \%$ for CSF. The ELISA-d test proved to be efficient for the diagnosis of neurocysticercosis, mainly when carried out in CSF, with the advantages of good stability, easy preparation and exe cution and low cost.

\section{AGRADECIMENTOS}

Agradecemos aos Dr. Aluízio de Barros Bar reto Machado, Dr. Gilberto Eduardo Bassi e a Dra. Isabel Domicilia Vaz, do Laboratório Central do Hospital das Clínicas da Faculdade de Medicina da Universidade de São Paulo; ao Dr. Marcos Vinicius da Silva do Hospital Emilio Ri bas e ao Dr. Ricardo Nitrini pelo fornecimento das amostras de soro e líquido cefalorraquiano.

\section{REFERENCIAS BIBLIOGRÁFICAS}

1. ARAMBULO III, P. V.: WALLS, K. W., BULLOCK, S. \& KAGAN, I. G. -- Serodiagnosis of human cysticercosis by microplate enzyme-linked-immunospecific assay (ELI SA). Acta trop. (BaseI), 35: 63 67, 1978.

2. BITTENCOURT, E.; GUIMARĀES, M.; CAMARGO, M E; FERREIRA, A. W. \& MAKINO, M. M. - Immunoassays conducted with resin treated nylon Fabrics. J. Poly. mer, Sci.: Polymer Letters Edition, 21: 717-722, 1983.

3. BRADFORD, M. M. - A rapid and sensitive method for the quantitation of microgram quantities of protein utili zing the principle of protein dye binding. Analyt. Biochem. 72: 248-252, 1976.

4. CAMARGO, M. E; BITTENCOURT, E; FERREIRA, A W.; PERES, L. \& CARVALHO, M. B - Utilização de resinas sobre suportes inertes para fixação covalente de com ponentes antigénicos ou anticorpos, como fase sólida em testes sorológicos. In: Jornada Científica do Instituto de Medicina Tropical de São Paulo, 2, São Paulo, 1983. Resu $\operatorname{mos} p 21$

5. COKER.VANN, M. R.; BROWN, P. \& GAJDUSEK, D C. - Serodiagnosis of human cysticercosis using a croma tofocused antigenic preparation of Taenia solium cysti cerci in an enzyme linked immunosorbent assay (EILISA). Trans. roy. Soc. trop. med. Hyg, 78: 492-496, 1984.

6. COSTA, J. M. - Teste imunoenzimático (E.LISA) no diagnóstico da neurocisticercose. Sào Paulo, 1983 (Tese de doutoramento -- Instituto de Ciencias Biomédic as da Uni versidade de São Pauloı.

7. DIWAN, A. R ; COKER VANN, M.; BROWN, P ; SUBIAN TO, I. B : YOLKEN, R.; LESOWITZ, R.; ESCOBAR, A. GIBRS, C. J. \& GAJDUSEK, D. C. .. Enzyme linked im 
VAZ, A. J. \& FERREIRA, A. W. -- Imunodiagnóstico da neurocisticercose: teste imunoenzimático com antígenos quimicamente ligados a suportes para pesquisa de anticorpos em soro e líquido cefalorraquiano.

Rev. Inst. Med. trop. São Paulo, 30 (1): $1-10,1988$.

munosorbent assay (ELISA) for the detection of antibody to cysticerci of Taenia solium. Amer. J. trop. Med Hyg. 31: $364 \cdot 369,1982$

8. GALEN, R. S. \& GAMBINO, S. R. - Beyond normality: the predictive value and efficiency of medical diagnosis. New York, John Wiley, 1975

9. LANGE, O.-- Sindrome liquórica da cisticercose encefalo meningea Rev, Neurol. Psiquiat. S. Paulo, 6: 3548,1940

10. LIVRAMENTO, J. A.; COSTA, J. M; MACHADO, L. R.; NOBREGA, J.P.S. \& SPINA-FRANÇA, A .- ELISA IIgG e IgM) no LCR e soro na neurocisticercose em tratamento com praziquantel. Arch. Neuro-psiquiat. (S. Paulo), 43 267.274 .1985$.

11. MILLER, B. L.; STAUGAITIS, S. M; TOURTELLOTTE W. W : SHAPSHAK, P.; GOLDBERG, M ; MEINER, D \& WEIL, M. - Intra-blood-brain barrier IgG synthesis in cerebral cysticercosis. Arch. Neurol. (Chic.), 42: 782-784, 1.985

12. MOHAMMAD, I. N.: HEINER, D. C.; MILLER, B. L.; GOLDBERG. M. A. \& KAGAN. I. G.-Enzyme-linked immunosorbent assay for the diagnosis of cerebral cysti cercosis J. clin. Microbiol. 20 775 779. 1984

13. OBERHAUSER, E. \& WEINSTEIN V - Estudio compa rativo de liquido cefalorraquideo y sangre en lués y cisti cercosis cerebral. Acta neurol. Iat. amer., 14; 7482.1968

14. PAUL, J, R. \& WHITE, G. - Serological epidemiology. London. Academic Press. 1973

15. PERES, L. - Desenvolvimento e caracterização de imu nosorventes e avaliação de desempenho em ensaios imu noenzimáticos. Campinas, 1986 (Dissertaçāo de mestrado - Faculdade de Engenharia da Universidade de Campinas).

16. SCOTT, T. A. \& MELVIN, E. H. Determination of dex tran with antrone. Analyt. Chem., 25: 1656-1661, 1953.

17. SPINA-FRANCA, A - Imunobiologia da cisticercose: avaliação dos conceitos atuais. Arch. Neuro-psiquiat. (S. Paulo), 27 125-140, 1969

Recebido para publicaçăo em 22/09/1987 